\title{
INFLUÊNCIA DE SISTEMAS DE REFRIGERAÇÃO SOBRE A QUALIDADE DO SÊMEN OVINO CRIOPRESERVADO EM PALHETAS
}

\author{
Ligia Freitas de Lima, ${ }^{1}$ Priscilla Moura, ${ }^{1}$ Pedro Ivo Braga Passos,,${ }^{1}$ Diogo Ramos Leal, ${ }^{1}$ \\ Rodolfo Rumpf, ${ }^{2}$ Jairo Pereira Neves ${ }^{3}$ \\ 1. Pós-graduandos em Medicina Veterinária da UnB \\ 2. Pesquisador doutor da Embrapa Recursos Genéticos e Biotecnologia \\ 3. Professor doutor da Faculdade de Agronomia e Veterinária da UnB.
}

RESUMO

Avaliaram-se diferentes sistemas de refrigeração do sêmen ovino, através da aferição e comparação das curvas obtidas e seus efeitos sobre a qualidade do sêmen criopreservado. Ao final da refrigeração, os parâmetros espermáticos motilidade, vigor, defeitos morfológicos, viabilidade e estado acrossomal foram analisados. Para a avaliação pós-descongelação mais dois testes foram acrescentados: avaliação da integridade de membrana plasmática (IMP) e teste de exaustão com quatro horas de incubação $\mathrm{a}+37^{\circ} \mathrm{C}$. A refrigeração foi realizada em refrigerador doméstico e num balcão horizontal. Para controlar a queda de temperatura desses equipamentos, colocaram-se as palhetas entre bolsas plásticas contendo água aquecida $\mathrm{a}+32^{\circ} \mathrm{C}$, constituindo quatro sistemas: $\mathrm{RS}$ (refrigerador sem bolsa), RC (refrigerador com bolsa), BS (balcão sem bolsa) e BC (balcão com bolsa), os quais resultaram em quatro taxas de refrigeração: $-1,4^{\circ} \mathrm{C} / \mathrm{min},-0,4^{\circ} \mathrm{C} / \mathrm{min},-2,9^{\circ} \mathrm{C} /$ min e $-0,45^{\circ} \mathrm{C} / \mathrm{min}$, para $\mathrm{RS}, \mathrm{RC}$, BS e $\mathrm{BC}$, respectivamente. Após a refrigeração, observou-se diferença na motilidade espermática $(\mathrm{P}<0,05)$, em que BS apresentou menor média. O sistema BS obteve a menor média de vivos íntegros e também a maior de mortos íntegros ao final da refrigeração, diferindo de RC e BC. Quanto aos defeitos morfológicos pós-refrigeração, $\mathrm{BS}$ apresentou maior média $(\mathrm{P}<0,05)$, ao passo que $\mathrm{RC}$ e $\mathrm{BC}$ apresentaram as menores médias. Não foram observadas diferenças significativas entre os tratamentos na descongelação e ao final do teste de exaustão. Concluiu-se que as diferentes taxas de refrigeração afetaram o sêmen no final da fase de refrigeração, mas não após a descongelação.

PALAVRAS-CHAVES: Congelação, ovino, protocolos-refrigeração, sêmen.

ABSTRACT

\section{INFLUENCE OF COOLING SYSTEMS ON THE QUALITY OF OVINE SEMEN CRYOPRESERVED IN STRAWS}

Different types of cooling systems of ram semen were evaluated by the measurement and comparison of cooling rates and their effects on the post-thawing quality. Motility, vigor, morphology damages, viability and acrosomal status were tested at the end of 90 minutes of cooling and post-thawing. Regarding post-thawed semen, the same parameters were used, in addition to the assessment of the integrity of the plasmatic membrane, and the resistance test by the incubation of semen at $+37^{\circ} \mathrm{C}$ for 4 hours. Semen refrigeration was carried out in a domestic refrigerator and in a horizontal refrigerator. To control the temperature drop of semen in both equipments, the slats were disposed between plastic bags containing water at $+32^{\circ} \mathrm{C}$, constituting four combi- nations of cooling procedures: RS (refrigerator without bag), RC (refrigerator with bag), BS (horizontal refrigerator without bag) and $\mathrm{BC}$ (horizontal refrigerator with bag), resulting in four cooling rates: $-1.4^{\circ} \mathrm{C} / \mathrm{min},-0.4^{\circ} \mathrm{C} / \mathrm{min},-2.9^{\circ} \mathrm{C} / \mathrm{min}$ and $-0.45^{\circ} \mathrm{C} / \mathrm{min}$, for $\mathrm{RS}$, $\mathrm{RC}$, BS and BC, respectively. At the end of the cooling period, BS treatment showed the lowest percentage of sperm motility $(\mathrm{P}<0.05)$, the lowest mean of live spermatozoa with intact acrosome, and the highest mean of dead spermatozoa with intact acrosome $(\mathrm{P}<0.05)$. As for morphological defects, BS treatment had the highest mean whereas the systems $\mathrm{RC}$ and $\mathrm{BC}$ resulted in the lowest means. There was no significant difference among treatments in relation to frozen-thawed semen at the end of the resistant test. It was 
concluded that the different cooling rates affected ram semen at the end of cooling stage but not at post-thawing.

KEYWORDS: Cooling protocols, cryopreservation, ovine, semen.

\section{INTRODUÇÃO}

A inseminação artificial (IA) aliada à utilização do sêmen congelado é uma biotecnologia que oferece inúmeras vantagens aos sistemas de produção animal, principalmente para os programas de reprodução que visam à multiplicação de indivíduos de alto mérito genético, por conseguinte, de alto valor comercial. Embora o sêmen congelado venha sendo utilizado ao longo de cinquenta anos na indústria bovina, sua utilização na espécie ovina continua sendo limitada (CURRY, 2000; HOLT, 2000).

Atualmente nas fêmeas ovinas, os melhores índices de fertilidade com sêmen congelado são obtidos após IA por via laparoscópica, com deposição do sêmen diretamente no útero. Esta técnica é considerada como a responsável pela expansão do uso do sêmen na espécie (EPPLESTON \& MAXWELL, 1993). No entanto, tal técnica apresenta limitada aplicação a campo de forma rotineira, pois requer instrumental de custo elevado e mão de obra especializada. A técnica de IA cervical, por ser de baixo custo e de fácil execução, surge como alternativa, pois permitiria um uso mais expressivo do sêmen ovino congelado. Entretanto, a aplicação cervical também possui suas limitações, como a difícil transposição da cérvix da ovelha com seus anéis tortuosos, inabilidade dos espermatozoides criopreservados em atravessar a cérvix, em virtude da motilidade e da viabilidade reduzida no trato genital da fêmea, da maturação excessiva das membranas espermáticas, oriundas do processo de criopreservação, o qual promove aumento na população de espermatozoides capacitados e acrossomos reagidos (MAXWELL \& WATSON, 1996; SALAMON \& MAXWELL, 2000).

O processo de criopreservação requer a exposição dos espermatozoides a diversos fatores estressantes, como redução de temperatura, desidratação celular, congelação, descongelação e reidratação. Os métodos utilizados a campo para criopreservação de sêmen utilizam materiais simples como caixas de isopor com gelo ou refrigeradores para a refrigeração e caixas de isopor com nitrogênio líquido para a con- gelação que, embora viáveis, apresentam variações nas curvas de refrigeração e congelação. Nos últimos anos, vêm sendo testados aparelhos automatizados para a criopreservação de sêmen. Trata-se de aparelhos que possuem como principal proposta o fato de proporcionarem curvas de temperatura programáveis e homogêneas (GONZALEZ, 2004). Um ritmo homogêneo e constante é importante não apenas para se evitar o choque térmico nos espermatozoides, como também para a padronização das técnicas e obtenção de partidas mais homogêneas. RODELLO (2006), utilizando bolsas de água durante a refrigeração do sêmen ovino em geladeira, obteve qualidade espermática e queda de temperatura $\left(-0,5^{\circ} \mathrm{C} / \mathrm{mim}\right)$ semelhantes às conseguidas em sistema automatizado.

O processo de congelação é uma sequência de eventos, tais como diluição, refrigeração, congelação e descongelação, com diferentes fatores prejudiciais aos espermatozoides. Dessa forma, a refrigeração causa um tipo específico de alteração relacionada com a mudança de fase dos lipídios da membrana plasmática (WATSON, 2000) que é diferente das que ocorrem durante a congelação, como estresses osmóticos, químicos e mecânicos sobre as células (HAMMERSTEDT et al., 1990).

Com este trabalho, objetivou-se avaliar diferentes sistemas de refrigeração de sêmen ovino envazado em palhetas, refrigerador doméstico e um balcão refrigerador horizontal. Foram comparados os efeitos da utilização de um sistema isolante constituído de bolsas de água, com a função de evitar a ocorrência de choque térmico, preservando, assim, a viabilidade espermática. Além disso, caracterizaram-se as taxas de refrigeração obtidas nos sistemas, tendo em vista a obtenção de melhores resultados ao final do processo de criopreservação.

\section{MATERIAIS E MÉTODOS}

Colheitas e avaliação do sêmen

As colheitas e as criopreservações de sêmen foram realizadas no Laboratório de Reprodução Animal da Embrapa Recursos Genéticos e Biotecnologia, 
localizada na Fazenda Experimental Sucupira, Brasília, DF. Utilizaram-se três carneiros da raça Santa Inês, em idade adulta e boa condição corporal. Cada reprodutor foi submetido a um total de dez colheitas por meio de vagina artificial aquecida a $+42^{\circ} \mathrm{C}$. Analisaram-se os ejaculados considerando os seguintes parâmetros: volume, aspecto, turbilhonamento, motilidade, vigor, concentração e morfologia espermática. Os ejaculados utilizados no programa de criopreservação foram aqueles que apresentaram os seguintes padrões mínimos: volume $0,5 \mathrm{~mL}$, motilidade de $70 \%$, vigor $3 \mathrm{e}$ concentração de $3 \times 10^{9} \mathrm{sptz} / \mathrm{mL}$.

\section{Processamento do sêmen}

Após as avaliações iniciais dos ejaculados, procedeu-se à pré-diluição na proporção de 1:1 (sêmen/ meio diluidor) em meio de congelação glicina-gemaleite (GGL) (GONZALEZ, 1999) em temperatura de $+32^{\circ} \mathrm{C}$. Em seguida, os ejaculados foram misturados, formando-se um pool dos três carneiros. O sêmen foi, então, rediluído, ajustando-se a uma concentração final de $100 \times 10^{6}$ espermatozoides totais/doses e envazado em palhetas de $0,25 \mathrm{~mL}$. As palhetas foram refrigeradas e distribuídas de acordo com as seguintes técnicas de refrigeração: refrigerador sem bolsa de água - RS; refrigerador com bolsa de água - RC; balcão sem bolsa de água - BS e balcão com bolsa de água - BC.

\section{Sistemas de refrigeração}

Para a refrigeração de sêmen realizado em refrigerador doméstico, utilizou-se um aparelho Consul compacto, modelo CRC12A com capacidade de 120 litros, dentro do qual foram criados dois sistemas. $\mathrm{O}$ primeiro consistia na forma convencional de refrigeração de sêmen, onde o suporte com as palhetas era colocado diretamente no interior do equipamento. No segundo sistema, as palhetas eram dispostas entre bolsas contendo água, as quais serviam como um sistema isolante térmico. Estas, confeccionadas artesanalmente com sacos plásticos, possuíam as medidas do suporte das palhetas (Nutricell® - Campinas/SP), $37 \mathrm{~cm}$ de comprimento por $15 \mathrm{~cm}$ de largura. Para o processo de refrigeração foram utilizadas duas bolsas com volume de $200 \mathrm{~mL}$ e uma bolsa de $400 \mathrm{~mL}$ de água, dispostas e retiradas da seguinte maneira: após as bolsas estarem aquecidas a $+32^{\circ} \mathrm{C}$, a bolsa de $400 \mathrm{~mL}$ ficava embaixo do suporte e as outras duas por cima; após 35 minutos de refrigeração, retirava-se a primeira bolsa de cima, aos cinquenta minutos era removida a segunda bolsa e por último a bolsa de $400 \mathrm{~mL}$ era retirada com sessenta minutos de refrigeração, completando-se noventa minutos. A ordem de retirada das bolsas seguiu a metodologia descrita por RODELLO (2006), em que se utiliza um sistema isolante semelhante para refrigeração de sêmen ovino em geladeira Minitub® ${ }^{\circledR}$ 518C. Para a refrigeração em balcão, empregou-se um modelo horizontal com circulação forçada de ar e monitor de temperatura (ELO800/SPE). Utilizaram-se dois sistemas de refrigeração, sem bolsas e com bolsas de água e um período de noventa minutos. Considerando o modelo de suporte de palhetas utilizado no balcão horizontal, as medidas das bolsas de água diferiram daquelas usadas no refrigerador e possuíam $18 \mathrm{~cm}$ de comprimento e $15 \mathrm{~cm}$ de largura. Utilizaram-se duas bolsas de $250 \mathrm{~mL}$ por cima do suporte com as palhetas e uma bolsa de $400 \mathrm{~mL}$ em baixo. Passados 35 minutos de refrigeração era retirada a primeira bolsa de cima, aos 57 minutos removia-se a segunda bolsa e aos sessenta minutos a terceira bolsa, a de baixo.

Monitoramento das curvas de refrigeração

As temperaturas das curvas de refrigeração obtidas nos sistemas, refrigerador, refrigerador com bolsa, balcão e balcão com bolsa foram aferidas nas dez partidas com o uso de um termômetro digital HD 8802 modelo IT18 (Delta OHM) com sensor tipo K. O sensor foi inserido dentro de uma palheta contendo sêmen e o meio de congelação GGL (glicina-gemaleite) (Figura 1).

\section{Avaliações do sêmen refrigerado}

Ao final da refrigeração do sêmen, três palhetas de cada tratamento (RS, RC, BS e BC) foram reaquecidas $\mathrm{a}+37^{\circ} \mathrm{C}$ por trinta segundos e avaliadas subjetivamente quanto à motilidade $(0-100 \%)$ e vigor (0-5) por microscopia de luz. Uma alíquota de vinte microlitros de sêmen de cada palheta foi diluída em 1 $\mathrm{mL}$ de solução formol-salina para análise da morfologia espermática e armazenada em tubos eppendorfs de $1,5 \mathrm{~mL} \mathrm{a}+5^{\circ} \mathrm{C}$, para posterior leitura em microscopia de contraste de fase.

A avaliação da viabilidade e integridade do acrossomo foi determinada por microscopia de campo claro através da coloração dupla (Trypan-blue + 
Giemsa) segundo DIDION (1989), na qual se acrescentaram $20 \mu \mathrm{L}$ de sêmen a $20 \mu \mathrm{L}$ de Trypan-blue em tubo eppendorf por doze minutos. Desta amostra fez-se um esfregaço, fixado em metanol por cinco minutos, que, depois de seco, era imerso em Giemsa por 8 a 24 horas.

Foram contadas duzentas células por lâmina e classificaram-se os espermatozoides encontrados conforme a descrição que segue:

- espermatozoide vivo com acrossomo íntegro - cabeça rosada e acrossomo rosado escuro;

- espermatozoide vivo com acrossomo reagido - cabeça toda rosada e acrossomo rosado (descorado);

- espermatozoide morto íntegro - cabeça azul e acrossomo rosado escuro;

- espermatozoide morto reagido - cabeça toda azul acrossomo azul (descorado).

\section{Processo de criopreservação}

As bandejas contendo as palhetas foram transferidas para uma caixa de polietileno (isopor) contendo nitrogênio líquido a uma distância de $5 \mathrm{~cm}$ acima do nível no nitrogênio, permanecendo por 20 minutos, sendo, então, mergulhadas em nitrogênio líquido, acondicionadas em raques e armazenadas em botijão criogênico a $-196^{\circ} \mathrm{C}$.

\section{Descongelação do sêmen}

As amostras foram descongeladas a $+37^{\circ} \mathrm{C} \mathrm{du}-$ rante trinta segundos e depositadas em tubos de vidro de $5 \mathrm{~mL}$ mantidos aquecidos a $+37^{\circ} \mathrm{C}$, sendo avaliados os mesmos parâmetros do sêmen refrigerado, acrescidos de outros dois testes: integridade de membrana plasmática (IMP) e teste de exaustão. Analisaram-se três palhetas de cada sistema de refrigeração/congelação por partida.

Integridade de membrana plasmática

A integridade da membrana plasmática foi avaliada utilizando-se uma combinação das sondas fluorescentes diacetato de carboxifluoresceína (DIC) e o iodeto de propídio (IP), como descrito por HARRISON \& VICKERS (1990). Adicionram-se $10 \mu \mathrm{L}$ de sêmen descongelado a $40 \mu \mathrm{L}$ de uma solução preparada com a combinação de $10 \mu \mathrm{L}$ de formol salina tamponada, $10 \mu \mathrm{L}$ de DIC e $5 \mu \mathrm{L}$ de IP para $480 \mu \mathrm{L}$ de citrato de sódio a $2,94 \%$. Após a incubação por quinze minutos à temperatura ambiente, uma alíquota de $10 \mu \mathrm{L}$ dessa suspensão foi depositada entre lâmina e lamínula. Contaram-se duzentas células, por meio de um microscópio de epifluorescência, sendo os espermatozoides considerados com membrana íntegra quando corados com verde e com membrana lesada quando corados de vermelho ou verde e vermelho.

Teste de termo resistência (TTR)

As palhetas descongeladas foram submetidas a teste de exaustão a $+37^{\circ} \mathrm{C}$ durante 240 minutos (PAGANINI FILHO, 1997), não sendo acrescentado em nenhum momento meio de congelação. Procedeu-se às análises no momento da descongelação (hora 0) e aos 240 minutos (hora 4) de incubação.

\section{Delineamento experimental}

Os dados coletados foram analisados por meio do software SAS (Statistical Analysis System) (2004), utilizando-se o procedimento GLM (análise de variância), num esquema fatorial $2 \times 2$, considerando-se os efeitos dos sistemas de refrigeração, a presença ou não das bolsas de água e as interações entre eles. Quando algum efeito foi observado, utilizou-se o teste de média Duncan, considerando nível de significância de $\mathrm{P}<0,05$.

\section{RESULTADOS E DISCUSSÃO}

Na Figura 1 estão representadas as curvas de refrigeração obtidas nos quatro sistemas. $\mathrm{O}$ sistema em refrigerador doméstico sem bolsas de água (RS), grupo-controle, apresentou um descenso brusco de temperatura, caindo no primeiro minuto $-18^{\circ} \mathrm{C}$, provavelmente pelo fato de as palhetas ficarem em contato direto com o ambiente do refrigerador. Uma queda de temperatura semelhante foi relatada por RODELLO (2006), observando um descendo de $-19,3^{\circ} \mathrm{C}$ no primeiro minuto de refrigeração do sêmen ovino realizada em geladeira. RS teve queda média de $-1,4^{\circ} \mathrm{C} / \mathrm{min}$, após dezenove minutos atingiu $+5^{\circ} \mathrm{C}$, temperatura em que as palhetas permaneceram estabilizando por mais 71 minutos, até completar-se noventa minutos de refrigeração e estabilização.

O ritmo obtido no sistema refrigerador com bolsa $(\mathrm{RC})$ proporcionou uma queda média de $-0,4^{\circ} \mathrm{C} / \mathrm{min}$, alcançando $+5^{\circ} \mathrm{C}$ após 65 minutos; o sêmen permane- 
ceu estabilizando 25 minutos. Esta taxa é semelhante à encontrada por RODELLO (2006) na refrigeração em geladeira Minitub ${ }^{\circledR} 518 \mathrm{C}$ com bolsas de água, tendo conseguido um ritmo médio de $-0,5^{\circ} \mathrm{C} / \mathrm{min}$.

O sistema de refrigeração em balcão sem bolsas (BS) de água apresentou uma queda de temperatura ainda mais rápida, caindo $-21^{\circ} \mathrm{C}$ no primeiro minuto, tendo em média uma taxa de $-2,9^{\circ} \mathrm{C} / \mathrm{min}$, atingindo $+5^{\circ} \mathrm{C}$ após nove minutos, com período de estabilização de 81 minutos.

A taxa de refrigeração média conseguida no sistema balcão com bolsa foi de $-0,45^{\circ} \mathrm{C} / \mathrm{min}$, alcançando $+5^{\circ} \mathrm{C}$ depois de 59 minutos. As palhetas estabilizaram por 31 minutos.

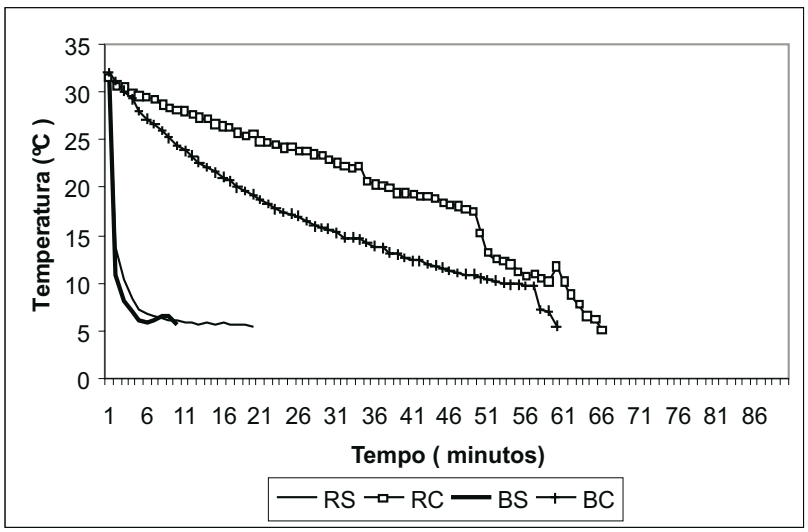

FIGURA 1. Curvas de refrigeração do sêmen ovino $\left({ }^{\circ} \mathrm{C} / \mathrm{min}\right)$ determinadas para a refrigeração em refrigerador sem bolsa (RS), refrigerador com bolsa (RC), balcão sem bolsa (BS) e balcão com bolsa (BC).

Para todos os parâmetros avaliados, não foram observadas interações entre sistema de refrigeração (refrigerador e balcão) $x$ sistema isolante (com bolsa e sem bolsa).

Comparando-se os quatro sistemas ao final do período de refrigeração do sêmen, foi observada diferença significativa $(\mathrm{P}<0,05)$ na motilidade espermática (Tabela 1). O grupo controle RS e os tratamentos RC e $\mathrm{BC}$ não diferiram entre si em relação à motilidade, $63,8 \%, 67,5 \%, 67,8 \%$, respectivamente. No entanto, o tratamento BS teve a menor média - 58,1\% (Tabela 1). Essa diferença na motilidade ocorreu em função das bolsas de água utilizadas $(\mathrm{P}<0,05)$ e não do tipo de sistema refrigerador (refrigerador ou balcão). $\mathrm{O}$ sistema BS foi o que apresentou a queda de tempera- tura mais rápida e possivelmente o sêmen refrigerado neste método possa ter sido prejudicado. É sabido que a refrigeração rápida do sêmen de $+30^{\circ} \mathrm{C}$ para $0^{\circ} \mathrm{C}$ (WATSON, 2000) e até mesmo a redução de temperatura de $+37^{\circ} \mathrm{C}$ para $5^{\circ} \mathrm{C}$ (LÓPEZ, 1999) induzem um estresse letal em algumas células, proporcional à taxa de refrigeração, intervalo de temperatura e ao limite de temperatura, conhecido como choque térmico. O choque térmico pode gerar rupturas na membrana plasmática que possibilitam a perda de cátions e enzimas dos espermatozoides, diminuindo de forma irreversível sua motilidade e atividade metabólica (WHITE, 1993). As alterações também incluem o decréscimo da glicólise e frutólise e, consequentemente, da respiração celular, e aumento da degeneração do ácido desoxirribonucleico (RODELLO, 2006). Trata-se de dados que estão de acordo com os relatados por OLLERO et al. (1998). Esses autores utilizaram uma taxa de refrigeração de $-0,25^{\circ} \mathrm{C} / \mathrm{min}$, no estudo dos efeitos da refrigeração, congelação e descongelação e da habilidade crioprotetora de quatro diluentes sobre o espermatozoide ovino, obtendo uma motilidade espermática subjetiva média pós-refrigeração de $62 \%$ em meio Tryladil-gema.

Para o vigor espermático, não houve diferença significativa entre os tratamentos após a refrigeração (Tabela 1).

A percentagem de espermatozoides vivos com acrossomo íntegro (VI) ao final dos noventa minutos de refrigeração apresentou diferença significativa entre os tratamentos $(\mathrm{P}<0,05)$. O método BS $(85 \%)$ teve menor média de vivos íntegros em relação aos demais, também havendo diferença significativa para o parâmetro morto com acrossomo íntegro (MI), sendo o tratamento BS aquele que obteve a maior média de espermatozoides mortos íntegros $(14,1 \%)$ (Tabela 1). Observa-se que a percentagem de vivos íntegros seguiu uma tendência da motilidade, reforçando a ideia de que o sistema BS possa ter diminuído a qualidade espermática, em virtude da queda brusca de temperatura. A diferença em relação às médias de espermatozoides VIU e MI deve-se ao uso das bolsas de água $(\mathrm{P}<0,05)$. Os quatro tratamentos não mostraram diferenças significativas quanto à percentagem de espermatozoides vivos com acrossomo reagido (VR) e percentagem de mortos com acrossomo reagido (MR) (Tabela 1).

A percentagem de defeitos de morfologia no sêmen fresco foi de $9,4 \pm 2,2 \%$, e após a refrigeração 
observou-se um aumento de defeitos nos quatro sistemas, com diferença significativa entre eles $(\mathrm{P}<0,05)$. $\mathrm{O}$ tratamento BS obteve a maior média de defeitos pósrefrigeração $(15,4 \%)$, ao passo que os tratamentos que utilizavam bolsas de água RC e BC tiveram as menores médias de defeitos morfológicos, $11,5 \%$ e $11,1 \%$, respectivamente. Já o grupo-controle RS $(13,6 \%)$ foi semelhante aos outros três tratamentos (Tabela 1). As transições de fase da membrana plasmática decorrentes da refrigeração rápida são responsáveis pelo aumento das alterações acrossomais e de defeitos de cauda (PARKS \& GRAHAM, 1992). Segundo BATEMAN (2001), que avaliou os efeitos de diluentes e métodos de refrigeração sobre a função do espermatozoide canino, a refrigeração do sêmen resulta num aumento de defeitos morfológicos principalmente da cauda do espermatozoide.

TABELA 1. Médias ( \pm desvio-padrão) da motilidade (\%), vigor (0-5), percentagem total de defeitos morfológicos dos espermatozoides (DM), percentagem de espermatozoides vivos com acrossomo íntegro (VI), mortos íntegros (MI), vivos com acrossomo reagido (VR), mortos reagidos (MR) do sêmen ovino refrigerado em diferentes sistemas ( $\mathrm{RS}$ - refrigerador sem bolsa, $\mathrm{RC}$ - refrigerador com bolsa, BS - balcão sem bolsa e BC - balcão com bolsa )

\begin{tabular}{cccccccc}
\hline & $\begin{array}{c}\text { Motilidade } \\
(\%)\end{array}$ & $\begin{array}{c}\text { Vigor } \\
(0-5)\end{array}$ & $\begin{array}{c}\text { DM } \\
(\%)\end{array}$ & $\begin{array}{c}\text { VI } \\
(\%)\end{array}$ & $\begin{array}{c}\text { MI } \\
(\%)\end{array}$ & $\begin{array}{c}\text { VR } \\
(\%)\end{array}$ & $\begin{array}{c}\text { MR } \\
(\%)\end{array}$ \\
\hline RS & $63,8 \pm 2,7^{\mathrm{a}}$ & $3 \pm 1,6$ & $13,6 \pm 3,3^{\mathrm{a}, \mathrm{b}}$ & $87,3 \pm 4,0^{\mathrm{a}, \mathrm{b}}$ & $11,7 \pm 4,1^{\mathrm{a}, \mathrm{b}}$ & $0,1 \pm 0,2$ & $0,9 \pm 0,4$ \\
RC & $67,5 \pm 4,9^{\mathrm{a}}$ & $3,1 \pm 1,6$ & $11,5 \pm 2,6^{\mathrm{b}}$ & $90,4 \pm 2,4^{\mathrm{a}}$ & $9,7 \pm 3,6^{\mathrm{b}}$ & $0,1 \pm 0,1$ & $0,8 \pm 0,5$ \\
BS & $58,1 \pm 9,5^{\mathrm{b}}$ & $3 \pm 1,6$ & $15,4 \pm 3,8^{\mathrm{a}}$ & $85,3 \pm 5,6^{\mathrm{b}}$ & $14,1 \pm 5,5^{\mathrm{a}}$ & $0,1 \pm 0,1$ & $1,2 \pm 2,1$ \\
BC & $67,8 \pm 4,9^{\mathrm{a}}$ & $3,9 \pm 0,3$ & $11,1 \pm 2,3^{\mathrm{b}}$ & $90 \pm 3,5^{\mathrm{a}}$ & $9,3 \pm 3,4^{\mathrm{b}}$ & $0,02 \pm 0,1$ & $1,3 \pm 2,0$ \\
\hline
\end{tabular}

a,b Médias, dentro da mesma coluna, seguidas de letras diversas, diferem entre si $(\mathrm{p}<0,05)$.

Após a descongelação do sêmen, não foi observada diferença significativa na motilidade e no vigor espermática entre os quatro tratamentos. Esse resultado sugere que o ritmo utilizado durante a refrigeração não exerceu efeito no sêmen após o processo de congelação, corroborando o relatado por JANUSKAUSKAS et al. (1999), que também não observaram diferenças entre duas taxas de refrigeração no sêmen bovino, lenta $\left(-0,1^{\circ} \mathrm{C} / \mathrm{min}\right)$ e rápida $\left(-4,2^{\circ} \mathrm{C} / \mathrm{min}\right)$, sobre a motilidade subjetiva após congelação automatizada. Está de acordo também com os resultados apresentados por BITTENCOURT et al. (2006), que não observaram diferença significativa nos parâmetros motilidade progressiva e total do sêmen caprino descongelado, após utilizarem a combinação entre duas taxas de refrigeração $\left(-0,46^{\circ} \mathrm{C} / \mathrm{min}\right.$ e $-1,07^{\circ} \mathrm{C} / \mathrm{min}$ ) e dois tempos de equilíbrio a $+5^{\circ} \mathrm{C}$ (uma hora e duas horas). No entanto, esses achados diferem dos achados de ROVAY (2006), que avaliou o efeito de dois protocolos de resfriamento para o sêmen caprino, usando dois ritmos de descenso $\left(-0,12^{\circ} \mathrm{C} / \mathrm{min}\right.$ e $\left.-0,4^{\circ} \mathrm{C} / \mathrm{min}\right)$, e obteve maior motilidade total pós-descongelação (54\%) com a curva $-0,4^{\circ} \mathrm{C} / \mathrm{mim}$.

A maioria das avaliações de viabilidade espermática verifica a integridade da membrana plasmática, pois uma membrana intacta e competente é fundamental para que um espermatozoide seja capaz de fecundar o oócito. Quando o espermatozoide é submetido à diminuição de temperatura durante as etapas da criopreservação, ocorre a desestabilização e até mesmo a ruptura da membrana, o que se deve à transição de fase desta, que passa de estado fluido para o de gel. Uma das consequências do rompimento da membrana é a perda de componentes intracelulares, tais como enzimas metabólicas e ATP, levando à morte da célula (JANUSKASUSKAS et al., 1999). Para os resultados da avaliação da IMP pós-descongelação, não foi observada diferença significativa entre os tratamentos RS, $\mathrm{RC}$, BS e BC $(16,8 \pm 5,1 \%, 13,4 \pm 4,9 \%, 13,8 \pm 4,2 \%$, $13,6 \pm 4,9 \%$, respectivamente) (Tabela 2). Segundo SALAMON \& MAXWELL (2000), após o processo de criopreservação a motilidade espermática pode variar entre $40 \%$ e $60 \%$, mas somente cerca de $20 \%$ a $30 \%$ dos espermatozoides mantêm-se com as membranas íntegras. No estudo realizado por RODELLO (2006), valores semelhantes aos dos autores anteriormente citados, para percentuais de células móveis $(50,1 \%$, $42,1 \%, 46,8 \%$ e $50,3 \%)$ e íntegras $(27,2 \%, 23,3 \%$, 
$25,5 \%$ e $27,4 \%$ ), pós-descongelação foram obtidos. O presente trabalho, no entanto, observou diferença considerável em relação a esses autores, pois a percentagem de células com membranas intactas foi menor que a metade da média de células que se apresentaram móveis no momento da descongelação. ALMEIDA (2006) sugere que, durante a criopreservação, os espermatozoides são submetidos a diversas condições desfavoráveis que prejudicam suas membranas muito antes de afetar sua motilidade.

Em relação à percentagem de defeitos morfológicos após a descongelação do sêmen, não se observou diferença significativa entre os tratamentos. No entanto, notou-se um aumento na percentagem de defeitos dos tratamentos com bolsa (RC e BC, $14,9 \%$ e $15,3 \%$; respectivamente), quando comparados aos valores após a refrigeração. Segundo BATEMAN (2001), a percentagem de espermatozoides com morfologia normal é diminuída levemente após a descongelação, concomitantemente com um aumento dos defeitos de cauda, sugerindo que a congelação e a descongelação tornam mais aparentes, principalmente, os defeitos de cauda gerados pela refrigeração.

É sabido que os processos de refrigeração, congelação e descongelação aceleram a maturação das membranas espermáticas, aumentando, assim, a proporção de espermatozoides capacitados e com acrossomos reagidos (SALAMON \& MAXWELL, 2000). Tal fato leva a uma diminuição da longevidade da célula espermática no trato genital da fêmea, podendo comprometer a fertilidade. GILLAN et al. (1997) relataram achados similares, com $61 \%$ de padrão $\mathrm{F}$ (não capacitado), 18\% para o padrão B (capacitado) e $21 \%$ padrão AR (acrossomo reagido) para o sêmen ovino fresco, em comparação com 7,2\% (F), 66\% (B) e $26 \%$ (AR) para o sêmen congelado-descongelado. No presente estudo, não foi observada diferença significativa entre os tratamentos na percentagem de espermatozoides vivos com acrossomo íntegro após a descongelação, sendo que os tratamentos RS, RC, BS e $\mathrm{BC}$ apresentaram $51,9 \pm 7,6 \%, 46,4 \pm 8,1 \%, 54 \pm 7,7 \%$ e 49,7 $\pm 8,7 \%$, respectivamente (Tabela 2 ).

Ficou evidenciada uma diminuição no número de vivos íntegros no sêmen descongelado quando comparado ao sêmen refrigerado. Mesmo com o aumento considerável de espermatozoides mortos com acrossomos íntegros nos quatro tratamentos após a congelação, não houve diferença significativa entre os tratamentos, nos percentuais de espermatozoides MI (Tabela 2). Quanto às percentagens de espermatozoides vivos com acrossomo reagido e mortos reagidos pós-descongelação, não foram observadas diferenças significativas entre os tratamentos (Tabela 2). Estes resultados estão de acordo com o estudo de GILLAN et al. (1997), os quais sugerem que as etapas de congelação e descongelação aumentam o número de espermatozoides capacitados, mas possuem menor efeito sobre o número de acrossomos reagidos.

TABELA 2. Média ( \pm desvio-padrão) da motilidade (\%), vigor (0-5), percentagem total de defeitos morfológicos dos espermatozoides (DM), percentagem de espermatozoides vivos com acrossomo íntegro (VI), vivos com acrossomo reagido (VR), mortos íntegros (MI), mortos reagidos (MR) e percentagem de células com membranas íntegras (IMP), do sêmen ovino refrigerado em diferentes sistemas (RS - refrigerador sem bolsa, RC - refrigerador com bolsa, BS - balcão sem bolsa, e BC - balcão com bolsa) e congelado em vapor de $\mathrm{N}_{2}$, logo após a descongelação

\begin{tabular}{ccccccccc}
\hline & $\begin{array}{c}\text { Motilidade } \\
(\%)\end{array}$ & $\begin{array}{c}\text { Vigor } \\
(0-5)\end{array}$ & $\begin{array}{c}\text { DM } \\
(\%)\end{array}$ & $\begin{array}{c}\text { VI } \\
(\%)\end{array}$ & $\begin{array}{c}\text { VR } \\
(\%)\end{array}$ & $\begin{array}{c}\text { MI } \\
(\%)\end{array}$ & $\begin{array}{c}\text { MR } \\
(\%)\end{array}$ & $\begin{array}{c}\text { IMP } \\
(\%)\end{array}$ \\
\hline RS & $41,2 \pm 6,2$ & $3 \pm 0$ & $13,5 \pm 1,5$ & $51,9 \pm 7,6$ & $0,1 \pm 0,2$ & $44,9 \pm 7,7$ & $3,2 \pm 0,9$ & $16,8 \pm 5,1$ \\
RC & $35,3 \pm 9,9$ & $2,9 \pm 0,1$ & $14,9 \pm 2,4$ & $46,4 \pm 8,1$ & $0,1 \pm 0,2$ & $50,1 \pm 8$ & $3,4 \pm 0,7$ & $13,4 \pm 4,9$ \\
BS & $40,2 \pm 5,7$ & $3 \pm 0,1$ & $15,3 \pm 2$ & $54 \pm 7,7$ & $0,3+0,4$ & $41,9 \pm 7,9$ & $3,7 \pm 1,7$ & $13,8 \pm 4,2$ \\
BC & $38,2 \pm 7,7$ & $3 \pm 0,1$ & $15,3 \pm 2,6$ & $49,7 \pm 8,7$ & $0,1 \pm 0,2$ & $47,6 \pm 9,2$ & $2,6 \pm 1,4$ & $13,6 \pm 4,9$ \\
\hline
\end{tabular}

O grau de dano espermático que ocorre nos espermatozoides durante o processo de criopreservação torna-se aparente durante a sua incubação.
Quanto maior esse dano, menor é a longevidade dessa célula no aparelho genital da fêmea (BAG et al., 2004). 
No tocante ao teste de exaustão, não foram observadas diferenças significativas na percentagem da motilidade e no vigor entre os quatro tratamentos ao final das quatro horas de incubação (Tabela 3). No entanto, notaram-se valores muito baixos para a motilidade espermática dos tratamentos, o que se deve, provavelmente, ao fato de as membranas espermáticas estarem muito lesadas no momento da descongelação. Estes resultados diferem de RODELLO (2006), que relatou, ao final do teste de exaustão do sêmen resfriado em refrigerador e congelado em vapor de $\mathrm{N}_{2}$ líquido, valor para motilidade de 32,1\%. Após a descongelação do sêmen ovino, a integridade de membrana foi drasticamente reduzida, ao passo que o efeito na motilidade não foi tão evidente. A análise simultânea da integridade de membrana e da motilidade revelou a existência de uma grande população de espermatozoides com danos de membrana que se apresentam móveis imediatamente após a descongelação. Os espermatozoides com membrana lesada, embora viáveis, perdem rapidamente a motilidade dentro de poucas horas de incubação a $+37^{\circ} \mathrm{C}$ (VALCÁRCEL et al., 1994). A diminuição da motilidade durante a incubação também pode estar ligada ao declínio na capacidade dos espermatozoides em gerar ATP, pelos danos mitocondriais, ou pelo efeito tóxico da enzima aminoácido oxidase aromático, liberado pelos espermatozoides mortos (JOSHI et al., 2005). Ao final do período de incubação também não se observou diferença significativa na percentagem de células com membranas íntegras entre os tratamentos (Tabela 3). A produção de radicais livres durante a estocagem do sêmen tem sido apontada como a principal causa da diminuição de motilidade e integridade espermática (VISWANATH \& SHANNON, 1997), declínio no metabolismo energético e na desnaturação do DNA do espermatozoide (BAUMBER et al., 2000). É sabido que, dentro de um sistema aeróbico ou parcialmente aeróbico, a produção de espécies reativas de oxigênios (ROS) é inevitável. Os radicais livres ânion superóxido $\left(\mathrm{O}_{2}^{-}\right)$, peróxido $\left(\mathrm{H}_{2} \mathrm{O}_{2}\right)$ e hidroxil $(\mathrm{OH})$ são os mais nocivos e as reações que geram estes radicais parecem mais ativas em temperaturas mais altas (BAG et al., 2004), sendo a temperatura utilizada no teste de exaustão bastante favorável. No presente estudo, a incubação do sêmen a $+37^{\circ} \mathrm{C}$ foi realizada após o descongelamento de uma palheta de $0,25 \mathrm{~mL}$ em um tubo de vidro de $5 \mathrm{~mL}$, e possivelmente o espaço entre a tampa do tubo e a superfície do sêmen proporcionou condições para o estabelecimento de um sistema aeróbico, que pode ter contribuído para baixos resultados no final da incubação.

A percentagem de defeitos de morfologia ao final do teste de exaustão também não apresentou diferença significativa entre os quatro tratamentos (Tabela 3 ). No entanto, notou-se um leve aumento de defeitos, de forma semelhante, nos quatro tratamentos RS, RC, BS e BC $(15,6 \%, 16,3 \%, 17,3 \%, 16,5 \%)$, quando comparados ao momento da descongelação do sêmen.

TABELA 3. Médias ( \pm desvio-padrão) da motilidade (\%), vigor (0-5), percentagem total de defeitos morfológicos dos espermatozoides e percentagem de células com membranas íntegras (IMP) ao final de quatro horas de teste de exaustão

\begin{tabular}{ccccc}
\hline & $\begin{array}{c}\text { Motilidade } \\
(\%)\end{array}$ & $\begin{array}{c}\text { Vigor } \\
(0-5)\end{array}$ & $\begin{array}{c}\text { DM } \\
(\%)\end{array}$ & $\begin{array}{c}\text { IMP } \\
(\%)\end{array}$ \\
\hline RS & $0,8 \pm 1$ & $0,4 \pm 0,5$ & $15,6 \pm 2,6$ & $10,6 \pm 3,5$ \\
RC & $1 \pm 1$ & $0,5 \pm 0,4$ & $16,3 \pm 2,8$ & $9,3 \pm 3,4$ \\
BS & $5,1 \pm 7,6$ & $1 \pm 1,3$ & $17,3 \pm 2,2$ & $8,9 \pm 3$ \\
BC & $1,3 \pm 1,7$ & $0,5 \pm 0,6$ & $16,5 \pm 2,8$ & $9,3 \pm 3,3$ \\
\hline
\end{tabular}

\section{CONCLUSÕES}

A utilização das bolsas plásticas contendo água durante a refrigeração do sêmen ovino é eficiente em controlar a queda de temperatura tanto no refrigerador quanto no balcão. As diferentes taxas de refrigeração obtidas influenciaram o sêmen após o período de refrigeração, mas a sua qualidade pós-descongelação não foi influenciada pelos diferentes protocolos de refrigeração. 


\section{REFERÊNCIAS}

ALMEIDA, J. L. Efeito de diferentes concentrações de plasma seminal na criopreservação de sêmen equino. Brasília, 2006. Tese (Mestrado em Ciências Agrárias) - Faculdade de Agronomia e Medicina Veterinária, Universidade de Brasília - UnB. Disponível em: $<$ http://www.agencia.cnptia.embrapa.br/recursos/almeidaIDyCx2ytALcl.pdf $>$.

BAG, S.; JOSHI, A.; NAQVI, S. M. K.; MITTAL, J. P. Effect of post-thaw incubation on sperm Kinematics and acrossomal integrity of ram spermatozoa cryopreserved in medium-sized French straws. Theriogenology, v. 62, p. 415-424, 2004.

BATEMAN, H. L. Effect of semen extenders composition and cooling methods on canine sperm function and cryo-survival. 2001. (Thesis) - Faculty of Graduate Studies of the University of Guelph. Ottawa/Canada, 2001. Disponível em: < http://www. collectionscanada.gc.ca/obj/s4/f2/dsk3/ftp04/MQ61869.pdf >

BAUMBER, J.; BALL, B. A.; GRAVANCE, C.G.; MEDINA, V.; DAVIES-MOREL, M. C. The effect of reactive oxygen species on equine sperm motility, viability, acrosomal integrity, mitochondrial membrane potential and membrane lipid peroxidation. Journal of Andrology, v. 21, p. 895-902, 2000.

BITTENCOURT, R.F.; RIBEIRO-FILHO, A.L.; ALVES, S. G. G.; BISCARDE, C. E.; VASCONCELOS, M. F.; OBA, E. O efeito do tempo de equilíbrio sobre a qualidade do sêmen caprino criopreservado. Revista Brasileira de Saúde e Produção Animal, v. 7, p. 27-37, 2006.

CURRY, M. R. Cryopreservation of semen from domestic livestock. Reviews of Reproduction, v. 5, p. 46-52, 2000.

DIDION, B. A.; DOBRINSKY, J .R.; GILES, J. R.; GRAVES, C. $\mathrm{N}$. Staining procedure to detect viability and the true acrosome reaction in spermatozoa of various species. Gamete Research, v. 22, n. 1, p. 51-57, 1989.

EPPLESTON, J.; MAXWELL, W. M. C. Recent attempts to improve the fertility of frozen ram semen inseminated into the cervix. Wool Technology Sheep Breeding v. 41, p. 291-302, 1993.

GILLAN, L.; EVANS, G.; MAXWELL, M. C. Capacitation status of fresh and frozen-thawed ram spermatozoa. Reproduction, Fertility and Development, v. 9, n. 5, p. 481-488, 1997.

GONZALEZ, C. I. M.; OBA, E.; BICUDO, S. D. Avaliação do sêmen ovino (Ovis aries) congelado em palhetas e pellets com diferentes meios diluidores In: CONGRESSO BRASILEIRO DE REPRODUÇÃO ANIMAL, 13., 1999, Belo Horizonte, MG, 1999. Anais... Belo Horizonte: Revista Brasileira de Reprodução Animal, v. 23, n. 3, p. 280-281, 1999.
GONZALEZ, R. A. F. Efeito da criopreservação utilizando diferentes técnicas de criopreservação e crioprotetores sobre parâmetros espermáticos e a integridade de membranas do espermatozoide bovino. Pirassununga, 2004. Tese (Doutorado em Medicina Veterinária) - Faculdade de Medicina Veterinária e Zootecnia, Universidade de São Paulo. Disponível em: <http:// www.teses.usp.br/teses/disponiveis/10/10131/tde-19102004101719/pt-br.php>.

HAMMERSTEDT, R. H.; GRAHAM J. K.; NOLAN J. P. Cryopreservation of mammalian sperm: what we ask them to survive. Journal of Andrology, v. 11, p. 73-88, 1990.

HARRISON, R. A. P.; VICKERS, S. E. Use of fluorescent probes to assess membrane integrity in mammalian spermatozoa. Journal of Reproduction and Fertility, v. 88, p. 343-52, 1990.

HOLT, W. V. Basic aspects of frozen storage of semen. Animal Reproduction Science, v. 62, p. 2-33, 2000.

JANUSKAUSKAS, A.; GIL, J.; SÖDERQUIST, L.; HÅÅRD, M. G. M.; HÅARD, M. Ch.; JOHANNISSON, A.; RODRIGUEZMARTINEZ, H. Effect of cooling rates on post-thaw sperm motility, membrane integrity, capacitation status and fertility of dairy bull semen used for artificial insemination in Sweden Theriogenology, v. 52 , p. $641-658,1999$.

JOSHI, A.; BAG, S.; NAQVI, S. M. K.; SHARMA, R. C.; MITTAL, J. P. Effect of post-thawing incubation on sperm motility and acrosomal integrity of cryopreserved Garole ram semen. Small Ruminant Research, v. 56, p. 231-238, 2005.

LÓPEZ, A.; SÖDERQUIST, L.; RODRIGUEZ-MARTINEZ, H. Sperm viability in ram semen diluted and stored in three different extenders. Acta Veterinaria Scandinavica, v. 40, p. 1-9, 1999.

MAXWELL, W. M. C.; WATSON; P. F. Recent progress in the preservation of ram semen. Animal Reproduction Science, v. 42, p. 55-65, 1996.

OLLERO, M.; PEREZ-PE, R.; MUIÑO-BLANCO, T.; CEBRIANPEREZ, J. A. Improvement of ram sperm cryopreservation protocols assessed by sperm quality parameters and heterogeneity analysis. Cryobiology, v. 37, p. 1-12, 1998.

PAGANINI FILHO, P.; BICUDO, S. D.; SOUZA, M. I. L.; SOUSA, D. B. Viabilidade do sêmen ovino frente a três diluidores em temperatura de $37^{\circ} \mathrm{C}$ e sob refrigeração. In: CONGRESSO BRASILEIRO DE REPRODUÇÃO ANIMAL, 12., 1997, Caxambu, MG. Anais... Belo Horizonte: Revista Brasileira de Reprodução Animal. v. 21, n. 2, p. 61-4, 1997.

PARKS, J. E.; GRAHAM, J. K. Effects of cryopreservation procedures on sperm membranes Theriogenology, v. 38, p. 209-222, 1992. 
RODELLO, L. Validação de sistema automatizado de refrigeração e congelação de sêmen ovino. Botucatu, 2006. Tese (Mestrado em Medicina Veterinária) - Faculdade de Medicina Veterinária e Zootecnia, Universidade Estadual Paulista, UNESP, 2006. http:/www.emparn.rn.gov.br/contentproducao/aplicacao/ emparn... - 147k.

ROVAY, H. Efeito de diferentes curvas de resfriamento, tempos de equilíbrio e crioprotetores permeáveis no congelamento de espermatozoides de caprinos. Viçosa, 2006. Tese (Mestrado em Zootecnia) - Universidade Federal de Viçosa-UFV, 2006. http:// caatinga.ufersa.edu.br/index.php/acta/article/viewPDF... - -1k -

SALAMON, S.; MAXWELL, W. M. C. Storage of ram semen. Animal Reproduction Science, v. 62, p. 77-111, 2000.

VALCÁRCEL, A.; HERAS, M. A.; PÉREZ, L.; MOSES, D. F.; BALDASSARE, H. Fluorescent staining as a method of assessing membrane damage and post-thaw survival of ram spermatozoa. Theriogenology, v. 41, p .483-489, 1994.

VISHWANATH, R.; SHANNON, P. Do sperm cells age? A review of the physiological chance in sperm during storage at ambient temperature. Reproduction, Fertility and Development, v. 9, p. 321-331, 1997.

WATSON, P. F. The causes of reduced fertility with cryopreserved semen. Animal Reproduction Science, v. 60-61, p. 481-492, 2000 .

WHITE, I. G. Lipids and calcium uptake of sperm in relation to cold shock and preservation: a review. Reproduction, Fertility and Development, v. 5, p. 639-658, 1993.

Submetido em: 10 jul. 2008. Aceito em: 10 nov. 2010. 